ISSN: 2578-3335 (Print) 2578-3343 (Online)

\title{
Impact of the Affordable Care Act on the Cooper Women's Care Center
}

Amanda Malik

Cooper University Healthcare, malik-amanda@cooperhealth.edu

Natali Franzblau

Cooper University Healthcare, franzblau-natali@cooperhealth.edu

Cooper Rowan Medical Journal: https://rdw.rowan.edu/crjcsm

Would you like to be a reviewer? Please fill in this short form to express your interest.

\section{Recommended Citation}

Malik, Amanda and Franzblau, Natali (2019) "Impact of the Affordable Care Act on the Cooper Women's Care Center," Cooper Rowan Medical Journal: Vol. 1 : Iss. 1 , Article 1.

DOI: 10.31986/issn.2578-3343_vol1iss 1.1

Available at: https://rdw.rowan.edu/crjcsm/vol1/iss1/1

\section{(c) (i)}

This work is licensed under a Creative Commons Attribution 4.0 License.

This Original Clinical Investigations is brought to you for free and open access by the Rowan University Journals at Rowan Digital Works. It has been accepted for inclusion in Cooper Rowan Medical Journal by an authorized editor of Rowan Digital Works. For more information, please contact brush@rowan.edu. 
Impact of the Affordable Care Act on the Cooper Women's Care Center

This original clinical investigations is available in Cooper Rowan Medical Journal: https://rdw.rowan.edu/crjcsm/vol1/ 


\title{
Did the Affordable Care Act Impact Care Provided at the Cooper Women's Care Center?
}

\author{
Amanda Malik $^{1}$ \& Natali Franzblau ${ }^{2}$ \\ ${ }^{1}$ Obstetrics and Gynecology, Cooper University Hospital, Camden, NJ \\ ${ }^{2}$ Department of Obstetrics \& Gynecology, Cooper Medical School of Rowan University, Camden, New \\ Jersey \\ E-mails: malik-amanda@cooperhealth.edu (Amanda Malik), franzblau@rowan.edu (Natali Franzblau)
}

\section{INTRODUCTION}

The Affordable Care Act (ACA) was passed by Congress and signed into law by President Obama in March of 2010. The purpose was to increase access to health insurance, improve and standardize the quality of care in the US, and reduce overall costs of our healthcare system. The law includes several provisions that have direct impact on women and the practices that provide their care. Under the legislation, preventive services for women must be covered by health insurance companies at no cost to the patient. The list of services includes annual well woman visits, HPV testing, annual counseling for STIs and HIV, contraceptive counseling and methods, and screening for domestic and interpersonal violence. Federally sponsored health insurance programs began covering these screenings shortly after the ACA was signed, and beginning August 2012, all new and non-grandfathered private insurance plans were required to cover these services as well. ${ }^{1}$

In addition to emphasizing preventive care, the ACA made health insurance mandatory, imposing fines for those who do not obtain insurance. The ACA also facilitated the ability to purchase insurance through exchanges, and provided incentives for individual states to expand eligibility for Medicaid. Prior to ACA, Medicaid eligibility was restricted to low-income children, pregnant women, the elderly, and individuals with disabilities. Thirty-one states and the District of Columbia opted to expand Medicaid, and in those states low-income adults became eligible. In New Jersey, Medicaid was expanded to include all adults with an income below $138 \%$ of the federal poverty line. This expansion had the potential to greatly impact women who had previously been uninsured as well as the providers who serve Medicaid enrollees. Currently there is mixed evidence on the impact of ACA on services provided and how it may have changed the populations accessing care. Lau and colleagues found that post-ACA, young adults had 
significantly increased rates of preventive visits, including annual dental visits, routine examinations, and blood pressure and cholesterol screenings. However, the same population had unchanged rates of other preventive services, such as influenza vaccination. ${ }^{2}$ Research by Barbarescu and co-investigators also suggests that the ACA's mandated cost-free preventive coverage did not lead to a significant increase in use of these services, at least among young adults. ${ }^{3}$ Early research into the impact of the ACA on women's utilization of preventive reproductive services appear to be insignificant, ${ }^{4}$ but previous research regarding access by women shows that cost-free coverage, particularly of contraception, does increase its use. In states such as Delaware and Iowa where contraceptive coverage was mandated prior to the ACA, women were $5 \%$ more likely to use effective contraception than in states without such laws. ${ }^{5}$

This study aimed to assess changes in the utilization of Women's Health services as well as changes in the demographics of patients at the Cooper Women's Care Center (WCC) in pre- and post- ACA time periods. The WCC is part of the Cooper University Healthcare system and is located in Camden, NJ. The clinic patient population primarily consists of the underserved women who live in and around Camden, one of the poorest cities in the United States. Many patients rely on Medicaid or Charity Care (a hospital care payment assistance program). The clinic is primarily staffed by trainees of the Cooper Obstetrics and Gynecology post-graduate training program, supervised by a licensed physician, and accepts all insurances, including Medicaid.

We hypothesize that ACA changes led to an increase in the proportion of gynecology visits at the Cooper WCC. Secondarily, we evaluated whether the demographics of women served by the WCC changed after implementation of the ACA.

\section{PATIENTS/METHODS}

This study utilizes an observational cross-sectional design. The study was approved by the Cooper Institutional Review Board via the expedited study process. We selected two time periods of equal length to represent pre- and post- ACA implementation, based on data available from the IDX billing system in use at Cooper through 2015. The first time period was January 1, 2005-December 31, 2009; the second was January 1, 2011-December 31, 2015. The selection of these two time periods provided a "washout" year of 2010, the year in which the ACA was signed into law and its provisions began to take effect. All patients seen at the Cooper Women's Care Center in the two aforementioned time periods were included; no other initial exclusion criteria was used. Variables collected included patient Medical Record Number (MRN), date of service, patient date of birth, race, insurance type, visit type (gynecology or obstetrics), and diagnosis code. Data was kept on a secured Microsoft Excel sheet.

Data from each time period was initially sorted by visit type (gynecologic or obstetric) and diagnosis code 
and simple calculations were performed to determine what percentage of the total each type represented. Fischer's exact test was then used to determine significance. For demographic analysis, duplicate patients were first removed, using MRN to identify duplications. MRN was then removed in order to de-identify all data. Remaining data was used to calculate average age over both time periods, and then sorted by race and by insurance status. We used the Student $\mathrm{T}$ test and Chi-square analysis to determine significance of changes between the two time periods for age and race.

\section{RESULTS}

Our results show a significant increase in the gynecologic visits in the post-ACA period going from 23,171 pre-ACA (2005-2009) to 42,243 post-ACA (2011-2015). The distribution of visits, obstetric versus gynecologic also changed. Data in table 1 shows from 2005-2009 (pre-ACA period), $62.70 \%$ of total visits at the Cooper WCC were gynecology, while 37.30\% were obstetrics. From 2011-2015 (post-ACA period), $71.4 \%$ of total visits were gynecology and the remaining $28.6 \%$ were obstetrics. This change between time periods is statistically significant $(\mathrm{p}<0.0001)$. The breakdown of the total number of gynecology and obstetrics visits per year are shown on tables 2 and 3. Figure 1 provides annual trends of both obstetrical and gynecologic visits volume .

Table 1 Total visits by type, 2005-2009 and 2011-2015

\begin{tabular}{lll}
\hline Visit Type & $2005-2009$ & $2011-2015$ \\
Gynecology & $23,171(62.7 \%)$ & $42,243(71.4 \%)$ \\
Obstetrics & $13,786(37.3 \%)$ & $16,958(28.6 \%)$ \\
Total & 36,957 & 59,201 \\
\hline
\end{tabular}

Table 2 Total visits by type and year, 2005-2009

\begin{tabular}{lllllll}
\hline Visit Type & 2005 & 2006 & 2007 & 2008 & 2009 & Total \\
Gynecol- & 4,415 & 4,507 & 4,619 & 4,609 & 5,021 & 23,171 \\
ogy & $(69.5 \%)$ & $(68.4 \%)$ & $(59.4 \%)$ & $(57.9 \%)$ & $(60.8 \%)$ & $(62.7 \%)$ \\
Obstetrics & 1,941 & 2,087 & 3,163 & 3,354 & 3,241 & 13,786 \\
& $(30.5 \%)$ & $(31.6 \%)$ & $(40.6 \%)$ & $(42.1 \%)$ & $(39.2 \%)$ & $(37.3 \%)$ \\
Total & 6,356 & 6,594 & 7,782 & 7,963 & 8,262 & 36,957 \\
\hline
\end{tabular}

The average ages for 2005-2009 and 2011-2015 were 34.99 and 35.22 respectively, a non-statistical difference $(p=0.33)$ (Table 4$)$. The frequency and percent of total patients for each time period by race 
Table 3 Total visits by type and year, 2010-2015

\begin{tabular}{lllllll}
\hline Visit Type & 2011 & 2012 & 2013 & 2014 & 2015 & Total \\
Gynecol- & 4,283 & 4,960 & 8,667 & 11,647 & 12,686 & 42,243 \\
ogy & $(60.7 \%)$ & $(64.8 \%)$ & $(71.6 \%)$ & $(73.9 \%)$ & $(76.3 \%)$ & $(71.4 \%)$ \\
Obstetrics & 2,777 & 2,689 & 3,439 & 4,120 & 3,933 & 16,958 \\
& $(39.3 \%)$ & $(35.2 \%)$ & $(28.4 \%)$ & $(26.1 \%)$ & $(23.7 \%)$ & $(28.6 \%)$ \\
Total & 7,060 & 7,649 & 12,106 & 15,767 & 16,619 & 59,201 \\
\hline
\end{tabular}

Visit Type as Percent of Total, By Year

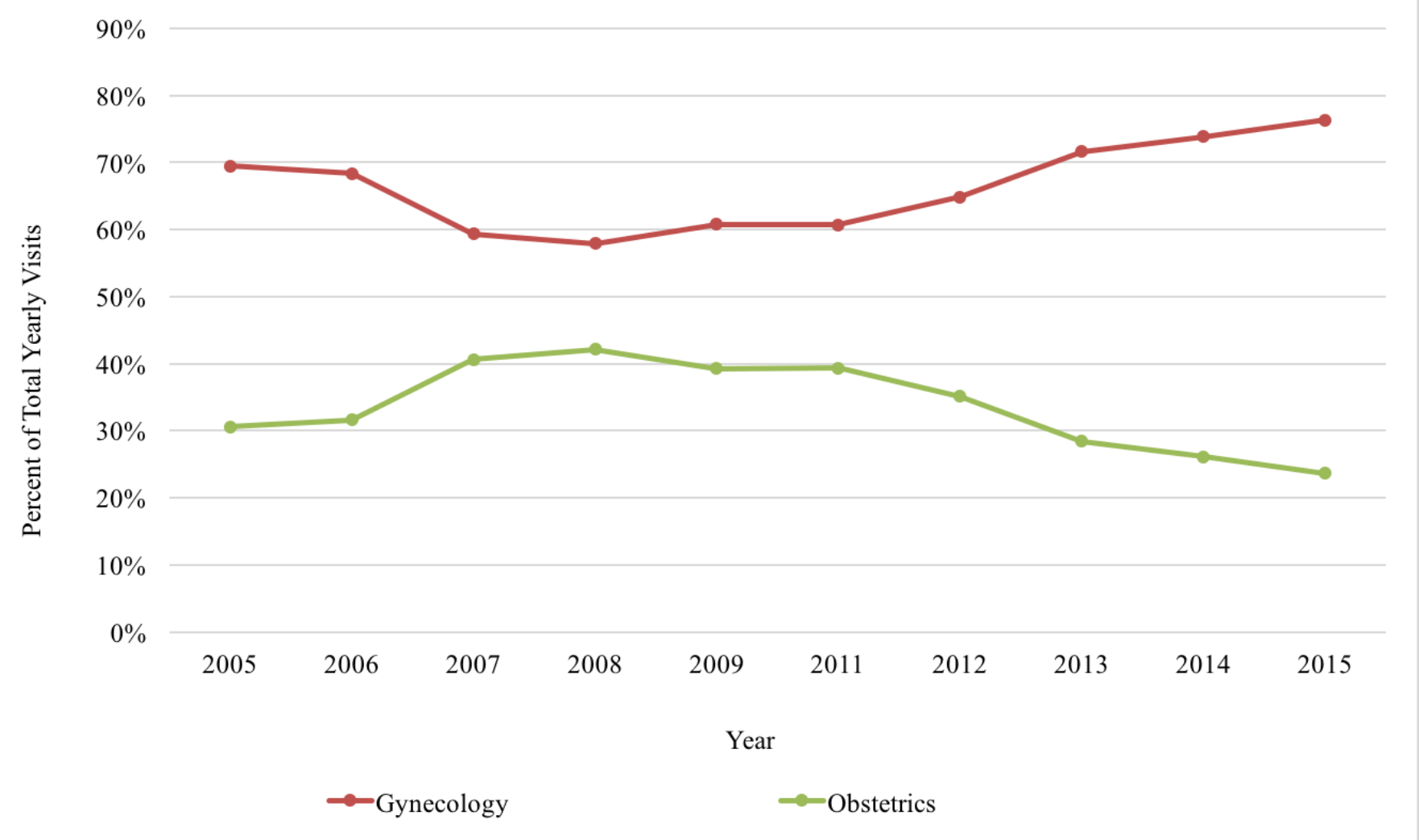

Figure 1 Visit Type as Percentof Total, By Year

showed only small changes, though the increase in Hispanic patients was statistically significant $(\mathrm{p}=$ 0.0042) (Table 5).

Table 4 Average age and standard deviation of patients

\begin{tabular}{lll}
\hline & $2005-2009$ & $2011-2015$ \\
\hline Mean Age & 34.99 & 35.22 \\
Standard Deviation & 14.55 & 14.69 \\
\hline
\end{tabular}

The breakdown of insurance types in both pre- and post- ACA time periods are also shown in table 5 . 
Table 5 Frequency and percent of Cooper WCC patients, by race and insurance type

\begin{tabular}{|c|c|c|c|c|c|}
\hline \multirow[t]{2}{*}{ Race } & 2005-2009 & Per- & 2011-2015 & Per- & $\mathrm{p}$-value \\
\hline & Frequency & cent & Frequency & cent & \\
\hline African American & 3105 & $41.35 \%$ & 2925 & $40.81 \%$ & 0.5093 \\
\hline Asian & 220 & $2.93 \%$ & 152 & $2.12 \%$ & 0.0019 \\
\hline Hispanic & 2372 & $31.59 \%$ & 2423 & $33.80 \%$ & 0.0042 \\
\hline Other & 280 & $3.73 \%$ & 234 & $3.26 \%$ & 0.1285 \\
\hline Unknown & & $0.89 \%$ & 24 & $0.33 \%$ & $<0.0001$ \\
\hline White & 1465 & $19.51 \%$ & 1410 & $19.67 \%$ & 0.8065 \\
\hline Insurance Type Charity & 1315 & $16.72 \%$ & 554 & $7.66 \%$ & 0.9530 \\
\hline \multicolumn{6}{|l|}{ Care } \\
\hline Commercial Insurance & 326 & $4.14 \%$ & 515 & $7.12 \%$ & 0.9005 \\
\hline Cooper Employee & 39 & $0.50 \%$ & 46 & $0.64 \%$ & 0.3843 \\
\hline $\mathrm{HMO}$ of $\mathrm{NJ}$ & 117 & $1.49 \%$ & 46 & $0.64 \%$ & 0.8438 \\
\hline Medicaid/Medicaid HMO & 5032 & $63.96 \%$ & 5157 & $71.28 \%$ & 0.9172 \\
\hline Medicare & 549 & $6.98 \%$ & 480 & $6.63 \%$ & 0.2340 \\
\hline NJBC & 103 & $1.31 \%$ & 108 & $1.49 \%$ & 0.2983 \\
\hline Other (including HMO) & 175 & $2.22 \%$ & 245 & $3.39 \%$ & 0.8181 \\
\hline Self Pay & 211 & $2.68 \%$ & 84 & $1.16 \%$ & 0.8823 \\
\hline
\end{tabular}

Medicaid/Medicaid HMO enrollees increased from 63.96\% in 2005-2009 to 71.28\% in 2011-2015 (p = 0.9172). Additionally, the percent of patients using charity care fell, from $16.72 \%$ to $6.77 \%$ ( $\mathrm{p}=0.9530$ ). However, none of these changes were statistically significant.

\section{DISCUSSION}

The key observation from this study was the significant increase in gynecologic visits at the Cooper WCC in the post versus pre ACA periods as well as the increasing \% of gynecologic versus obstetric visits. This latter finding would support that the increase in gynecologic visits is not a reflection of increasing volume due to growth of the clinic population since the obstetrics increase was minimal compared to the gynecologic. The cross-sectional design of this study does not allow assignment of cause and effect, but the trend of increasing gynecology visits corresponds closely to the implementation of the ACA. The trend lines are diverging, showing both an increase in the proportion of gynecology visits while at the same time a decrease in the proportion of obstetric visits. Although there is an overall increase in the total volume of 
visits that can be explained by the hiring of an additional provider in 2010, this does not explain the disproportionate rise in gynecology visits. The ACA provides two possible explanations for increasing gynecology visit volume. First, more people, including non-pregnant women without children, qualified for Medicaid in states such as NJ that chose to expand. Second, Medicaid and most other insurance plans were required to cover preventive services at no cost to patients including many services offered by gynecologists, such as annual well woman visits, HPV testing every 3 years, annual counseling for STIs and HIV, and contraceptive counseling and methods.

From 2011-2015, there is continuous rise in the percent of total visits that are gynecology, without a plateau that might be expected as newly qualified Medicaid beneficiaries and insurance enrollees level off. This might be explained by the progressive nature of the ACA; although the individual insurance mandate passed in 2010, penalties for not having insurance were not phased in until 2014, and then continued to rise through 2016. The phasing in of ACA policies over time necessitates longer periods of study to fully understand its effects.

Our secondary hypothesis, that the percent of patients covered by Medicaid would increase, is also supported by the data. The proportion of WCC patients using Medicaid increased by more than 7\%, and the percent of patients using charity care decreased, from $8.71 \%$ to $3.67 \%$. These trends also follow the implementation of the ACA changes. These insurance changes are important for financial planning at the level of the individual providers, offices and/or healthcare system. Our results are supported by the Kaiser Family Foundation, which found that states that expanded Medicaid experienced large increases in Medicaid enrollment, large reductions in uninsured rates, and only slight declines in private insurance coverage $^{6}$.

While we also hypothesized that the age of the patient population would increase, as more women who had no children or older children would now seek preventative care and gynecology care, the data did not bear this out.

\section{LIMITATIONS}

There are several limitations to our study. First, the cross-sectional design did not allow us to control for the many additional variables that likely impacted the data we examined, such as localized changes in pregnancy rates. While observational studies such as ours are convenient and inexpensive, there are many restrictions to the assumptions that can be made based on the results. Additionally, relying on historical data meant we were unable to fill gaps in missing data. For each analysis of age, race, and insurance type, several hundred patients had to be removed due to incomplete data.

A limitation in our study is the progressive nature of ACA policies, which were rolled out over several 
years. The staggered rollout of policies makes a simple before and after comparison difficult, especially considering the relatively short time that some regulations and policies have been in place. Many authors of early Medicaid expansion studies using only 2014 data note that changes in utilization are likely to need more than one or two years to materialize, and several longer studies note changes in later years that were not observed in earlier years ${ }^{6}$. We felt it was important to include year by year analysis of visit volume for this reason, though we were unable to control for the timeline of changes within the scope of this study. In addition to the implementation of ACA policies, several other changes took place between 2005-2015 that likely impacted the visit types and demographics of patients at the Cooper WCC. One such change was the addition of a nurse practitioner in 2010. The changing birth rate over the time periods selected, both at Cooper and in New Jersey, could have also impacted these numbers.

\section{CONCLUSIONS}

Over the last 7 years, the Affordable Care Act has had considerable impacts on our healthcare system, some of which are not yet fully elucidated. It will likely take several more years before the effects of new policies, both intentional and unintentional, become evident in the literature. However, it is already clear that women's health care has been affected by the ACA, due to the opportunities for increased insurance enrollment, especially in Medicaid expansion states, and the preventive services for women that are now covered at no cost to the individual. At the Cooper Women's Care Center, these national policy changes likely contributed to the increase in the percentage of gynecologic visits as well as the increase in patients using Medicaid. In clinics such as the Cooper WCC, it is clear that healthcare policies designed to increase access to preventive services can have an impact.

\section{REFERENCES}

1. Affordable Care Act Expands Prevention Coverage for Women's Health and Well-Being. (n.d.). Retrieved October 20, 2016, from http://www.hrsa.gov/womensguidelines/ Lau, J. S., Adams, S. H., Park, M. J.,

2. Boscardin, W. J., \& Irwin, C. E. (2014, December). Improvement in Preventive Care of Young Adults After the Affordable Care Act. JAMA Pediatrics, 168(12), 1101-1106. doi:10.1001/jamapediatrics.2014.1691 Barbaresco, S.,

3. Courtemanche, C., \& Qi, Y. (2015, March). Impacts of the Affordable Care Act Dependent Coverage Provision on Health-Related Outcomes of Young Adults. Journal of Health Economics,40, 54-68. doi:10.3386/w20148 Arora, P., \& Desai, 
4. K. (2016, August). Impact of Affordable Care Act coverage expansion on women's reproductive preventive services in the United States. Preventive Medicine,89, 224-229.

doi:10.1016/j.ypmed.2016.05.026 Atkins, D. N., \&

5. Bradford, W. D. (2014, January 16). Changes in State Prescription Contraceptive Mandates For Insurers: The Effect on Women's Contraceptive Use. Perspectives on Sexual and Reproductive Health,46(1), 23-29. doi:10.1363/46e0314

6. Antonisse, L., Garfield, R., Rudowitz, R. (2017, September 25). The Effects of Medicaid Expansion Under the ACA: Updated Finings from a Literature

7. Review. Kaiser Family Foundation. Retrieved December 1, 2017, from https://www.kff.org/medicaid/i ssue-brief/the-effects-of-medicaid-expansion-under-the-aca-updated-findings-from-a-literature-review-sep tember-2017/ 